Military Technical College Kobry Elkobbah, Cairo, Egypt

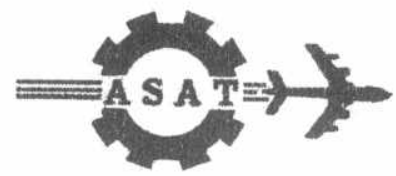

$8^{\text {th }}$ International Conference on Aerospace Sciences \& Aviation Technology

\title{
Experimental and Theoretical Study of the Static and Dynamic Behavior of a Variable-Displacement Pump with Power Control
}

\author{
Osama G. EI-Sayed*, M. Galal RABIE** and Refaat El-Taher***
}

\begin{abstract}
This paper deals with the static and dynamic behavior of a variable displacement bent axis axial piston pump with power controller. A mathematical model is deduced to predict the performance of the studied pump and its hydraulic servo controller. The developed model, which takes into consideration the basic pump and controller nonlinearities is used to develop a computer simulation program for the pump. The steady state flow-pressure characteristics and pump transient response are predicted by using the simulation program. The pump static and dynamic characteristics are also measured. The study showed good agreement between theoretical and experimental results. The study provides good foundation for the future work aiming at improving the pump performance by finding out optimum constructional parameters.
\end{abstract}

\section{KEY WORDS}

Pump - Hydraulic - Power - Control - Axial - piston - Servo - Static - Dynamic.

\section{NOMENCLATURE}

$A_{1} \quad$ Area of the first damping orifice.

$\mathrm{A}_{2} \quad$ Area of the second damping orifice.

$a_{3} \& a_{4} \quad$ Throttling areas of spool valve.

$A_{c} \quad$ Lower area of servo piston.

$A_{d n} \quad$ Throttle area connecting $n^{\text {th }}$ cylinder to delivery port.

Agdn Throttle area connecting $n^{\text {th }}$ cylinder to delivery port through relief groove.

$A_{\text {gsn }} \quad$ Throttle area connecting $n^{\text {th }}$ cylinder to suction port through relief groove.

$A_{p} \quad$ Piston area.

$A_{p p} \quad$ Area of the pressure sensing spool.

$A_{s} \quad$ Upper area of servo piston.

$A_{s n} \quad$ Throttle area conrecting $n^{\text {th }}$ cylinder to suction port through suction groove.

$A_{v} \quad$ Throttling area of the DCV.

* Lecturer, Mechanical Engineering Dpt., College of Engineering \& Petroleum, Kuwait Univ.

** Professor, Military Technical College, Cairo, Egypt

*** Professor, Faculty of Engineering, Zagazig Univ. 


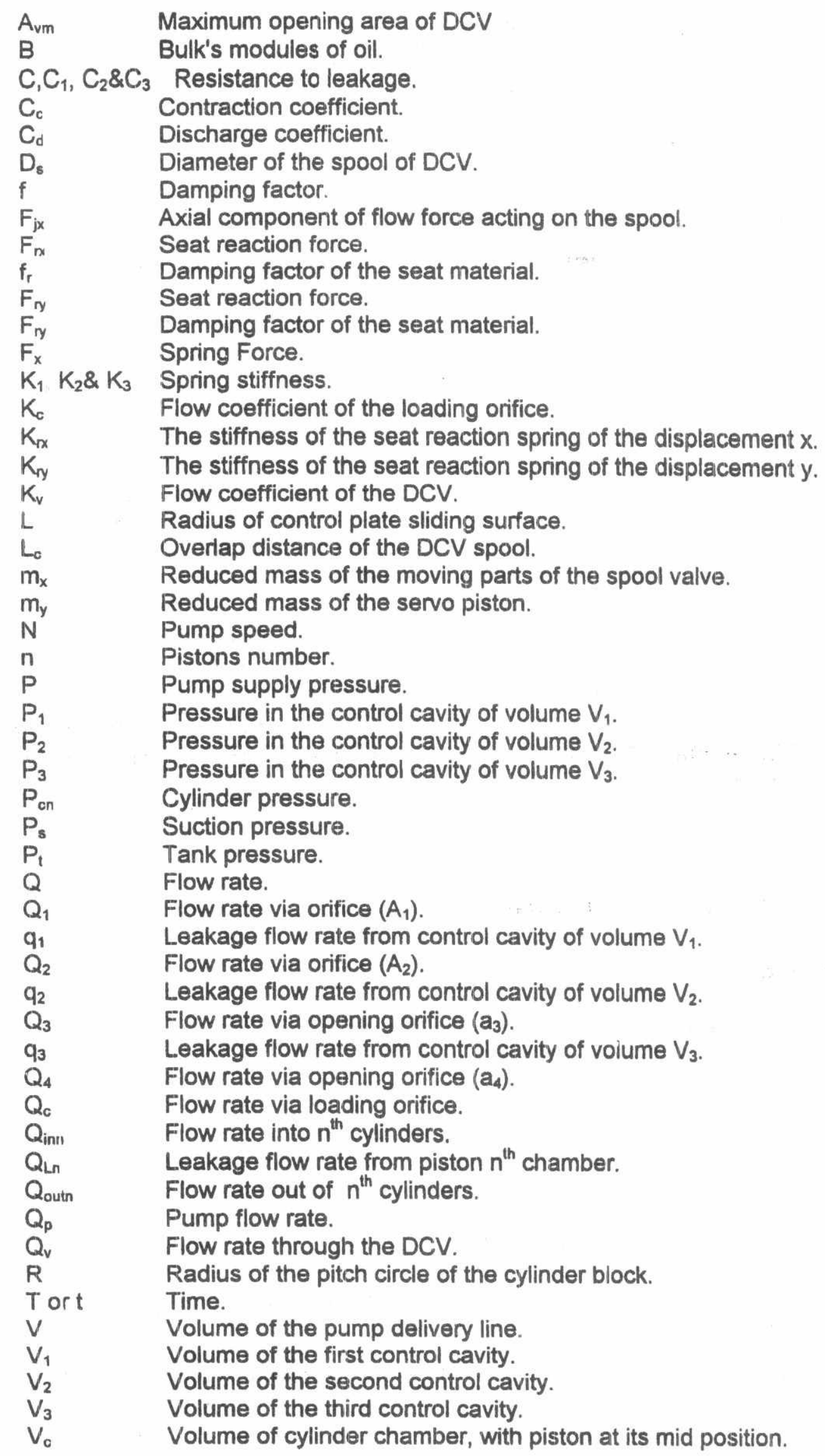




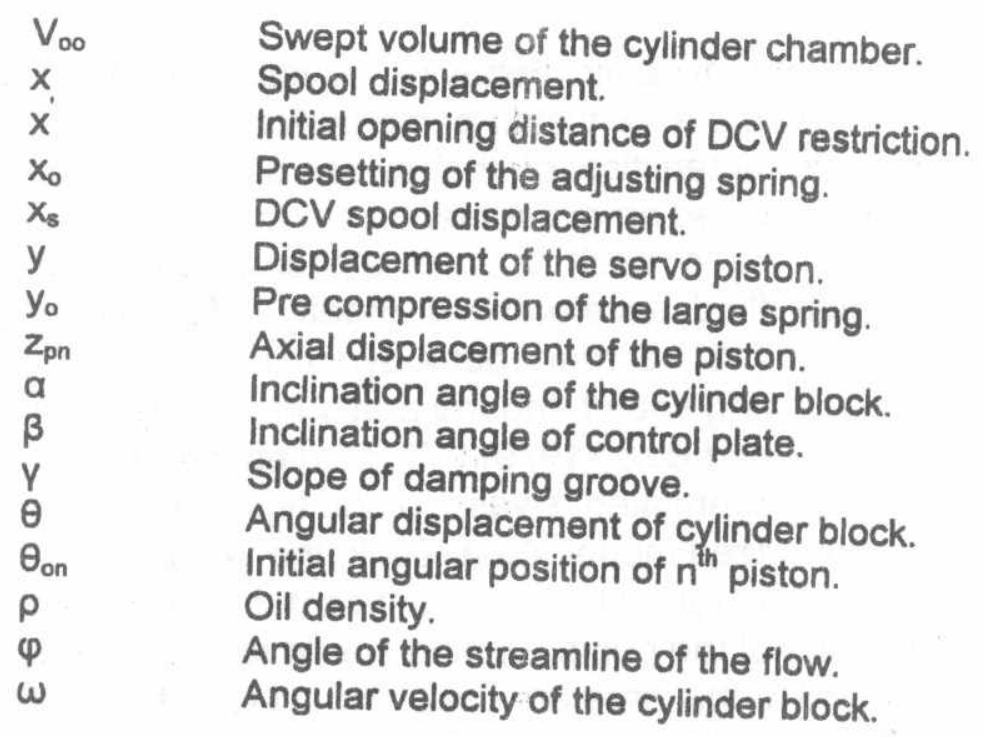

\section{ABBREVIATIONS}

$\begin{array}{ll}\text { HPS } & \text { High pressure side of the port plate. } \\ \text { LPS } & \text { Low pressure side of the port plate. } \\ \text { TDC } & \text { Top dead center of the port plate. } \\ \text { BDC } & \text { Bottom dead center of the port plate. } \\ \text { DCV } & \text { Directional control valve. } \\ \text { tdc } & \text { Top dead center of the cylinder. } \\ \text { bdc } & \text { Bottom dead center of the cylinder. }\end{array}$

\section{INTRODUCTION}

Among the widely used variable geometric pumps, one can distinguish the axial piston pumps. The displacement-varying mechanism and power-to-weight ratio of these pumps make them most suitable for control of high power levels. The continued development of fluid power system puts every-increasing demand upon these pumps for greater rotational speeds, delivery pressures and output power. In order to satisfy these demands many different aspects of their design received attention. The subject of the dynamics of these pumps is an important one and has been discussed by many researchers. Manring, (1998) [1], derived the instantaneous and average torque on the shaft of an axial piston swash plate type as a function of pump constructional and operational parameters. The author neglects the compressibility of the hydraulic fluid within the circuit. Manring and Johnson, (1996) [3], developed several simple equations that govern the design of the actuator and control gain of a variable-displacement pump. In this study, the swash plate inertia and damping are neglected. Kaliafetis, (1995) [4], studied the static and dynamic characteristics of a variable geometry axial piston pump with pressure regulator. The validity of the proposed model was based on the dynamic operating curves given by the manufacturer. The authors concluded that, the operating conditions are very crucial for the pump dynamic behavior. Kiyoshi, (1994) [5], 
conditions are very crucial for the pump dynamic behavior. Kiyoshi, (1994) [5], studied experimentally and theoretically the axial piston pump performance. He did not take into account the dynamic characteristics of the swash plate-supporting element. Edge, K. et al, (1989) [8], reported an experimental study of the cylincler pressure within an axial piston pump. As a result, during the change from inlet to delivery port and vice versa the high fluid accelerations greatly affect cylincler pressure and flow rate. Zeiger, (1986) [13], carried out a dynamic analysis of an axial piston pump and found that, the driving speed and the pressurized line volume affect the pump dynamic behavior. Zaki and Baz, (1979) [17], studied the static and dynamic characteristics of pressure compensated swash plate type. The study is based upon the development of a linearized model. As a result, the variation of the oil temperature within the normal operating range has no significant influence on the pump dynarnic behavior, while the effect of the pump running speed is considerable. Other researchers that have contributed to this area are Lin (1985) [14], Edge (1989) [9], Zhang (1989) [10], Kim (1987) [11] and Yamaguchi (1979) [16].

\section{PUMP DESCRIPTION AND OPERATION}

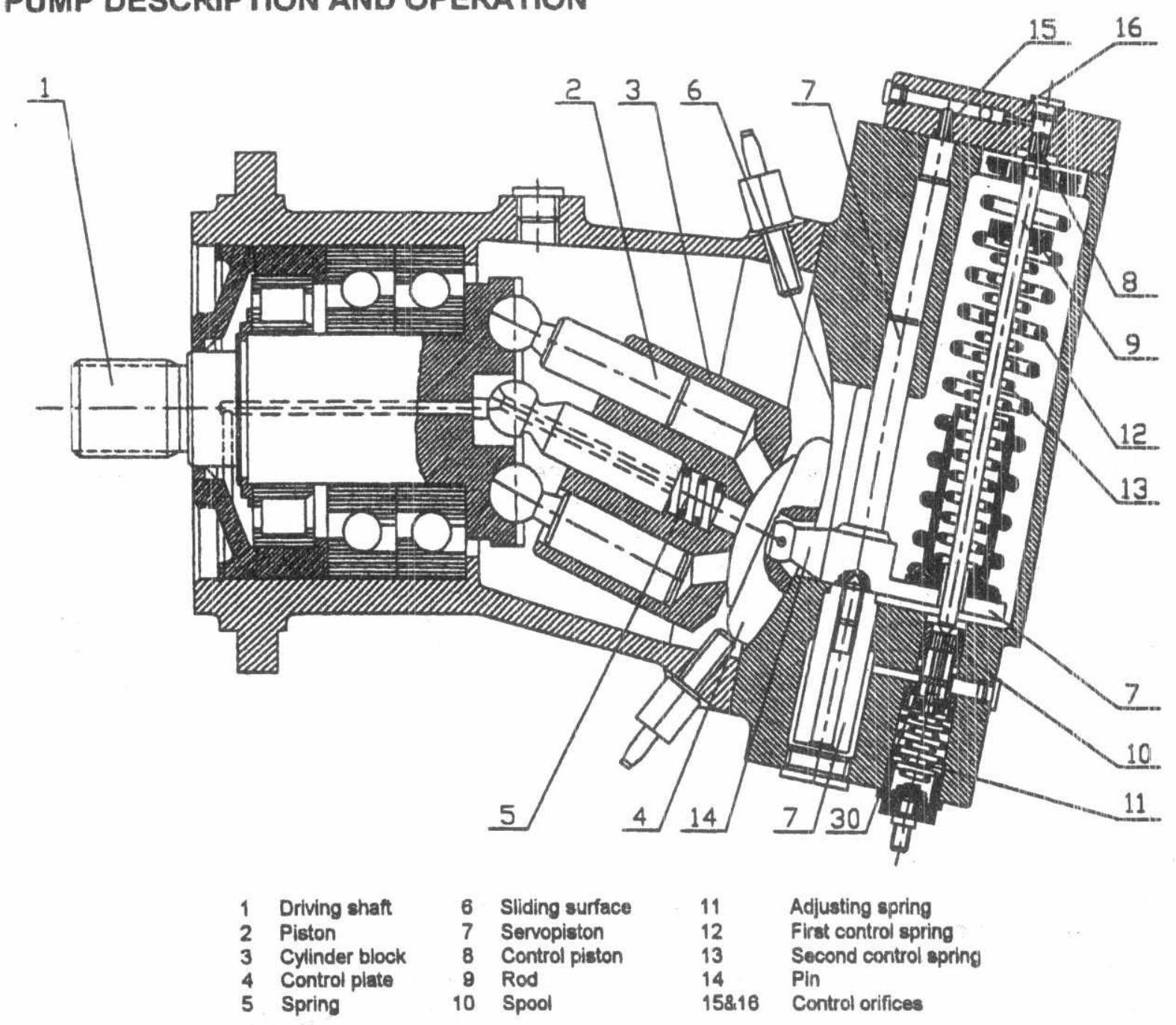

Fig.1. Scheme of the studied pump 
Figure 1, shows a scheme of the studied pump illustrating the basic components. The pump consists of two main groups. The first group is the pumping mechanism which include the driving shaft, valve plate and seven pistons within a common cylindrical block. The second group is the pump controller group, which contains servo piston, control piston, guide rod, spool valve, adjustment spring and control springs. The two groups are connected together by means of a pin 14. The upper side of servo piston is permanently connected to the pump delivery line through orifice 15. The lower side is connected to the pressure and return lines by means of the spool valve. When the operating pressure exceeds the value preset at the adjustment spring, the control piston, guide rod and spool move in the direction to connect the pressure line to the servo piston lower chamber. The servo piston moves upwards until the balance of pressure and spring forces is restored. In this way, the cylinder block reaches a new inclination angle corresponding to the delivery pressure.

\section{MATHEMATICAL MODEL}

The mathematical model describing the pump dynamic behavior is deduced considering the following assumptions.

- The fluid pressure at the suction and return lines is zero gauge pressure, neglecting the pressure losses in these short lines and using an open hydraulic tank.

- The pump rotates at constant speed.

- The oil temperature and viscosity are constant.

- The inertial effect of the oil column in a cylinder is negligible.

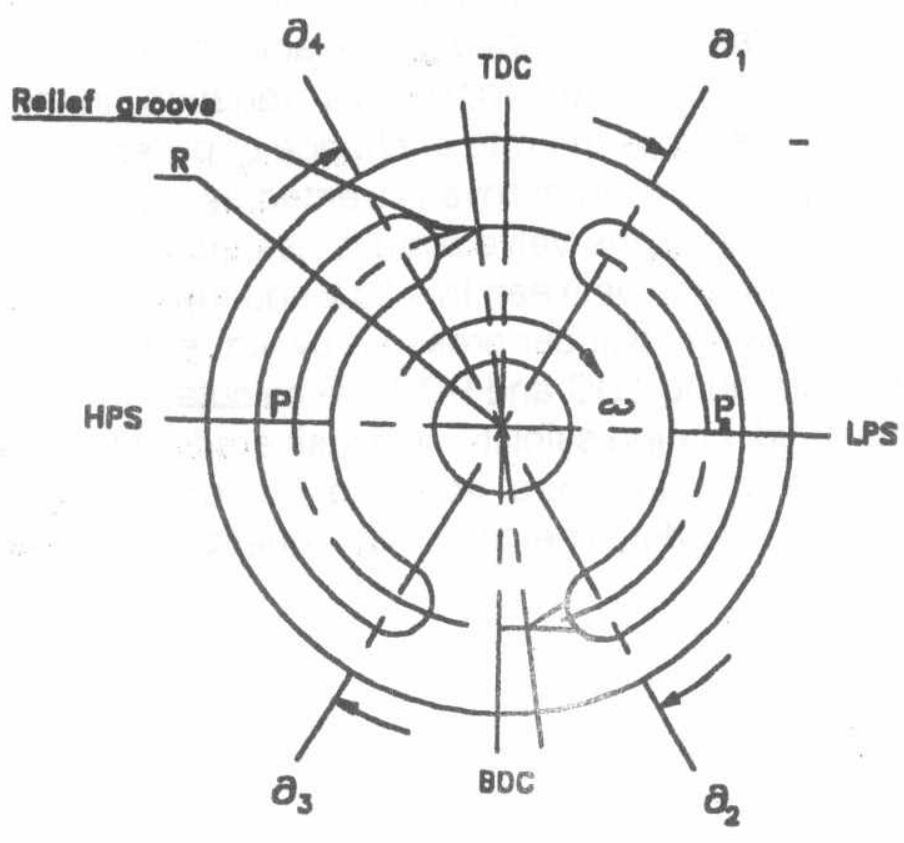

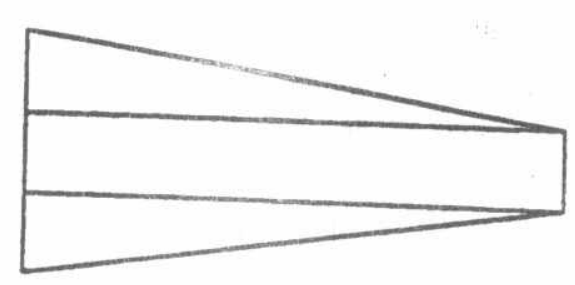

Plon

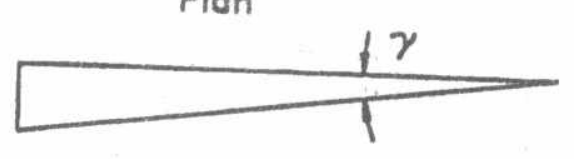

Front

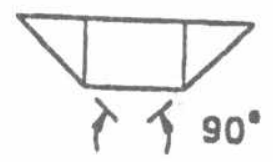

Side

Fig. 2. Port plate geometry 


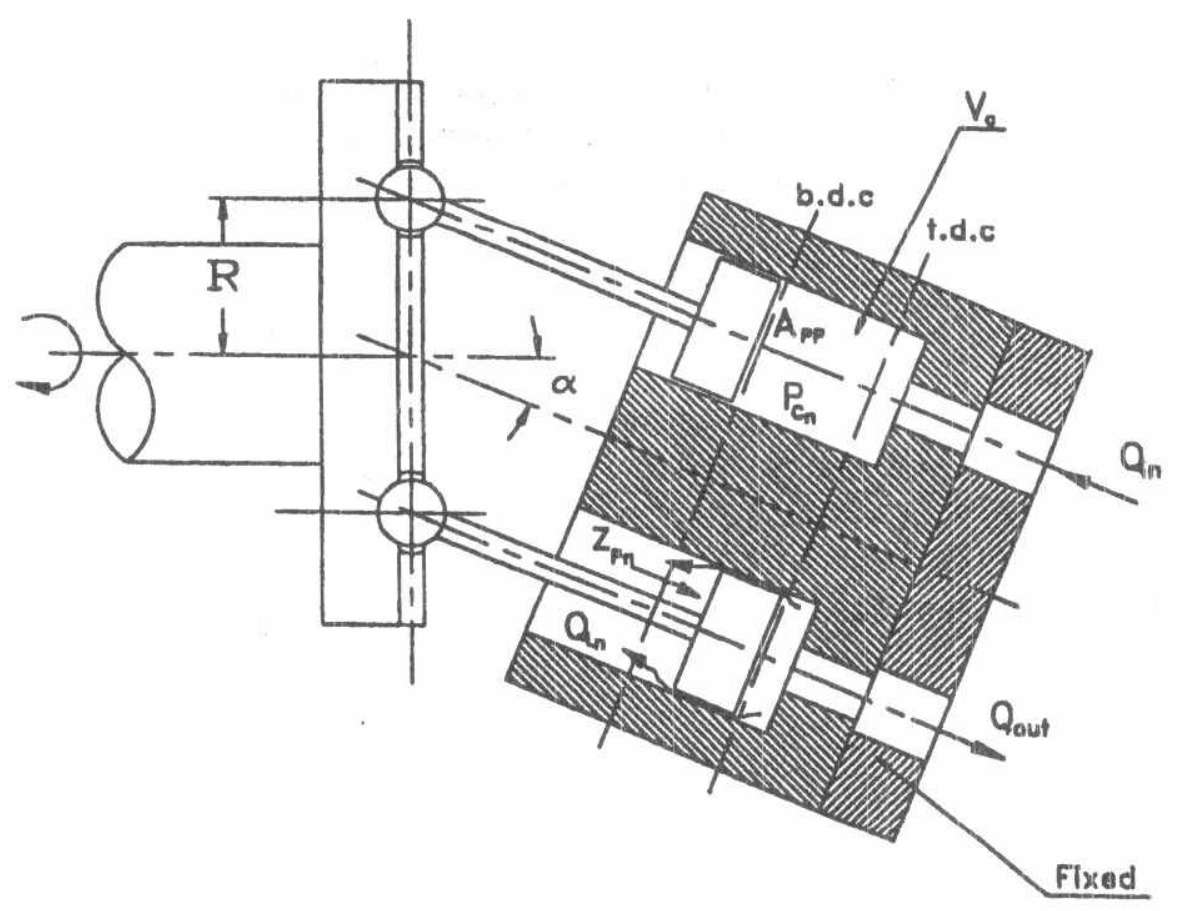

Fig.3. Scheme of the pumping mechanism

\section{Pressure in piston chambers}

The flow into and out of the cylinders is controlled by two kidney-shaped ports in the valve plate. These ports are connected to the pump suction and delivery lines, Fig. 2. The oil is drawn from the inlet port into the cylinder as the piston moves from top dead center (TDC), and is subsequently discharged through the other port following bottom dead center $(B D C)$. The relief grooves are machined in the land between the two ports. These grooves are designed to produce progressive variation in the effective flow area. This is desirable as it reduces the rate of change of pressure in the cylinder and the delivery flow ripples. The relief groove is treated as a variable area orifice [14]. The differential pressure across the valve plate is used to establish the flow into or out of the cylinder. The difference between this flow and the flow due to the motion of piston creates a change in cylinder pressure by virtue of the oil compressibility. So, the cylinder pressure around TDC and BDC are calculated using the continuity equation in which the fluid compressibility is considered. Also, the cylinder pressures at the other angular positions are equal to the pressure in delivery or suction port connected to the cylinder. The continuity equation in the $n^{\text {th }}$ cylinder is as follows:

$$
\frac{d P_{c n}}{d t}=\frac{B}{V\left(\theta_{n}\right)}\left(A_{p} \dot{z}_{p n}+Q_{l n n}-Q_{o u t n}-Q_{L n}\right)
$$

Within the transition regions, the chamber with high-pressure fluid $\mathrm{P}$ or low-pressure fluid $P_{\mathbf{s}}$ is open to the relief groove. The only fluid flow into the chamber is due to the 

piston motion. The high-pressure fluid tends to flow out of the chamber through the
relief groove. The flow rates $Q_{\text {outn }}$ and $Q_{\text {inn }}$ are given by:

$$
\begin{aligned}
& Q_{o u t n}=C_{d d} A_{d n} \sqrt{\frac{2}{\rho}\left|\left(P_{c n}-P\right)\right|} \operatorname{sign}\left(P_{c n}-P\right) \\
& Q_{l n n}=C_{d s} A_{s n} \sqrt{\frac{2}{\rho} P_{c n}} \\
& A_{d n}=A_{d n}^{\prime}+A_{g d n} \\
& A_{s n}=A_{s n}^{\prime}+A_{g s n}
\end{aligned}
$$

It is some what difficult to decide upon the values of $\mathrm{C}_{\mathrm{dd}}$ and $\mathrm{C}_{\mathrm{ds}}$ coefficients since for computational convenience they should be constant. The difficulty in specifying their value stems from the fact that the flow through the orifice is unsteady and the dimensions of the orifice are varying. For the mean values of relief groove dimensions, pressure differential and oil viscosity, a mean value of 0.7 could be considered [4]. The areas $A_{\text {dn }}^{\prime}$ and $A^{\prime}$ in are considering the control plate dimensions and relative position of the valve plate to the cylinder block. Both of them are function of angular displacement $\theta_{n}$. The studied pump has relief grooves of triangular $\mathrm{V}$-shaped, where the $\mathrm{V}$-angle is equal to $90^{\circ}$. Thus, the relief grooves orifice areas Agdn and $\mathrm{A}_{\text {gen }}$ are given by [14]

$$
\begin{aligned}
& A_{g d n}=R^{2}\left(\theta-\theta_{n}\right)^{2} \sin ^{2} \gamma_{d} \\
& A_{g s n}=R^{2}\left(\theta-\theta_{n}\right)^{2} \sin ^{2} \gamma_{s}
\end{aligned}
$$

The pump internal leakage changes with the working pressure. The resistance to leakage $\mathrm{C}$ is evaluated experimentally, and found to be constant along the whole operating pressure range. Therefore, the leakage flow could be calculated by the

$$
Q_{L n}=C P_{c n}
$$

The average leakage from a single cylinder could be estimated by taking total pump leakage flow rate, evaluated experimentally, and its relation to pressure then dividing it by $n / 2$. This technique is used to yield the average leakage from a single cylinder, assuming that on the average, half the number of pistons are exposed to high pressure and that most of the leakage originates at these cylinders. The volume of oil in the piston chamber is given by the following expression.

$$
V_{c}\left(\theta_{n}\right)=\left(V_{\infty}-A_{p} z_{p n}\right)
$$




\section{Piston Kinematics}

The piston displacement $z_{p n}$ yelocity and angular position displacement $\theta_{n}$ are given by the following equations, Fig. 3.

$$
\begin{aligned}
& z_{p n}=R \tan \alpha-(R \tan \alpha) \sin \theta_{n} \\
& \dot{z}_{p n}=R\left(\dot{\alpha} \sec ^{2}-\dot{\theta}_{n} \tan \alpha \cos \theta_{n}-\dot{\alpha} \sin \theta_{n} \sec ^{2} \alpha\right) \\
& \theta_{n}=\omega t+\theta_{\text {on }}
\end{aligned}
$$

The inclination angle $\alpha$ is given by the following equation, Fig. 4.

$$
\alpha=\left\{\begin{array}{lll}
\alpha_{\max } & \text { if } & y \leq 0 \\
\tan ^{-1}\left[\frac{\left(y_{\max }-y\right) \sin \beta}{L-\left(y_{\max }-y\right) \cos \beta}\right] & \text { if } & 0<y<y_{\max } \\
\alpha_{\min } & \text { if } & y \geq y_{\max }
\end{array}\right\}
$$

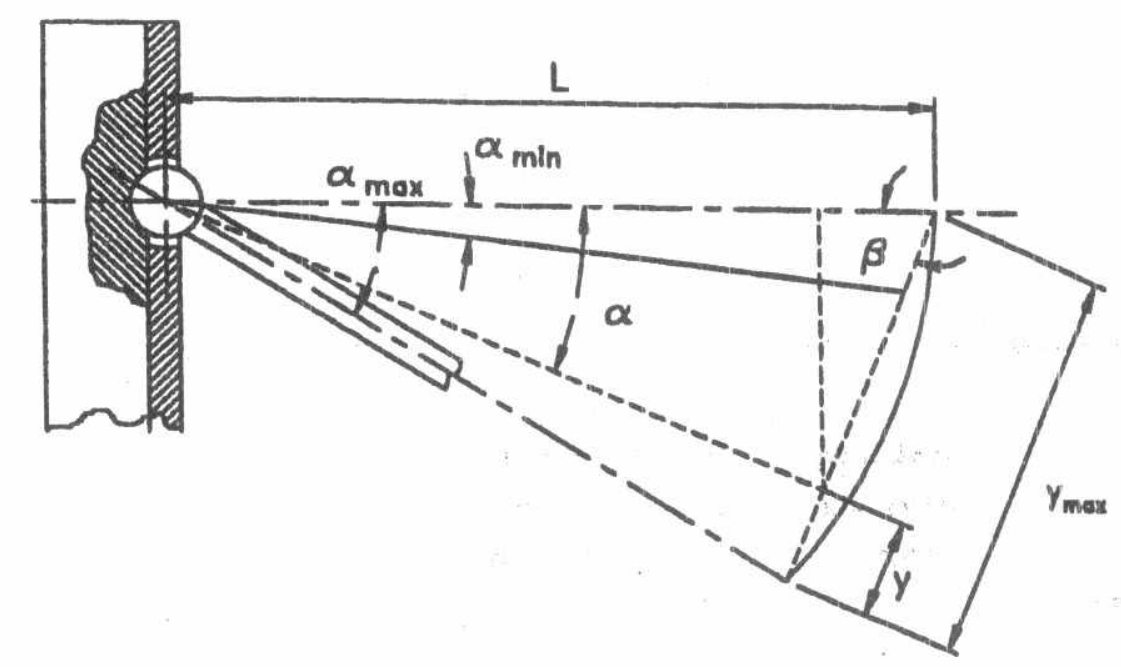

Fig.4. Inclination angle of cylinder block

\section{Controller Model}

A loading orifice and a directional control valve (DCV) are mounted on the discharge line of the pump, as shown in Figs.5\&6, to introduce a rapid change in the circuit load. The continuity equation as applied to the pump exit cavity of volume $V$ yields

$$
Q_{p}=Q_{c}+Q_{v}+Q_{1}+Q_{2}+\frac{V}{B} \frac{d P}{d t}
$$




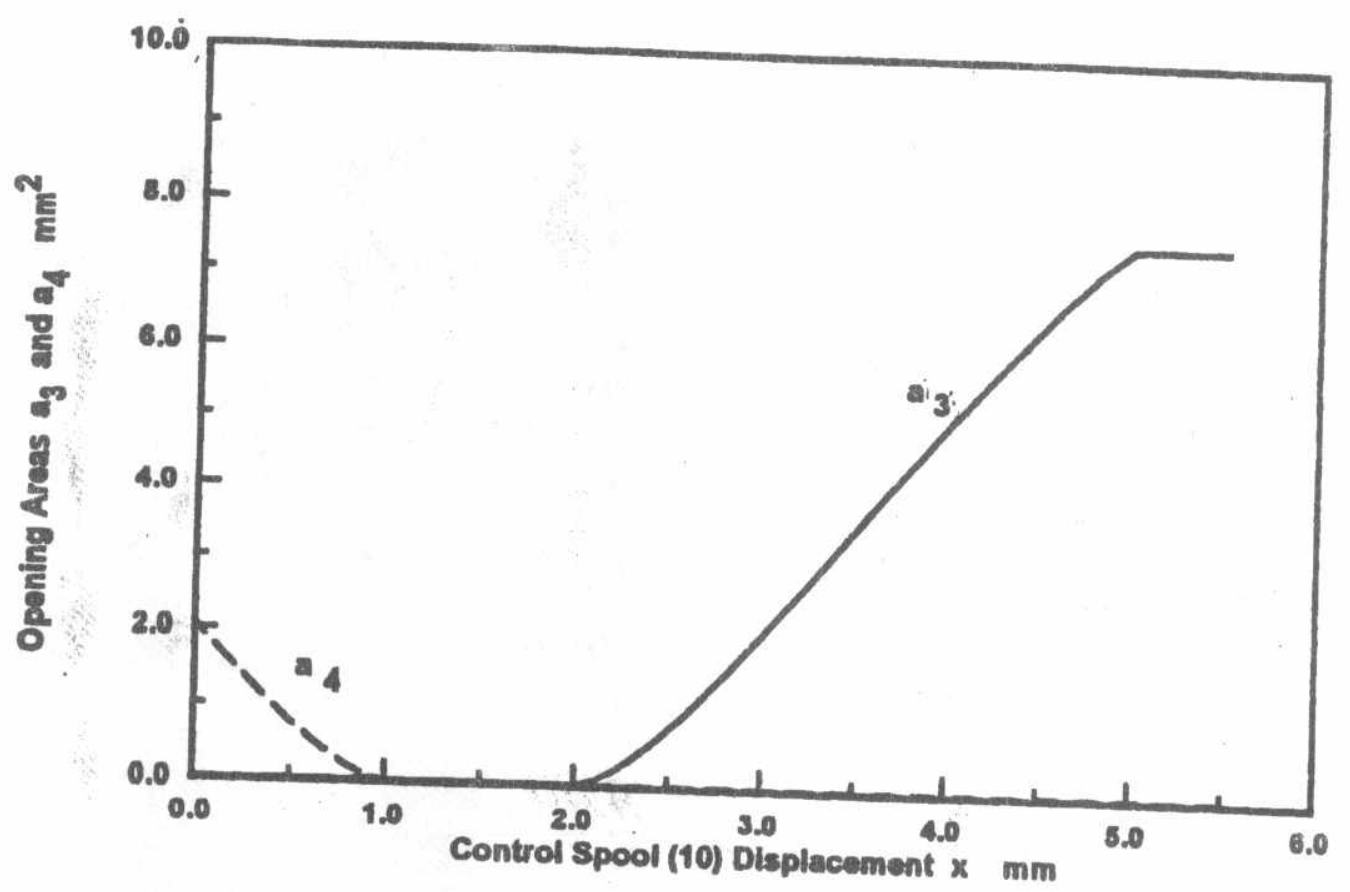

Fig.5. Variation of the spool valve restriction areas with the spool displacement. The pump flow rate $Q_{p}$ is given by:

$$
Q_{P}=\left(Q_{\text {out } 1}+Q_{\text {out } 2}+\ldots \ldots \ldots \ldots+Q_{\text {out }}\right)
$$

The flow rates $Q_{1}$ and $Q_{2}$ passing through damping orifices are given by the
following equations

$$
\begin{aligned}
& Q_{1}=C_{d 1} A_{1} \sqrt{\frac{2}{\rho} \mid\left(P-P_{1}\right)} \operatorname{sign}\left(P-P_{1}\right) \\
& Q_{2}=C_{d 2} A_{2} \sqrt{\frac{2}{\rho}\left|\left(P-P_{2}\right)\right|} \operatorname{sign}\left(P-P_{2}\right)
\end{aligned}
$$

The flow rate $Q_{c}$ and $Q_{v}$ are given by

$$
\begin{aligned}
& \mathrm{Q}_{\mathrm{c}}=\mathrm{K}_{\mathrm{c}} \sqrt{\frac{2}{\rho} P} \\
& \mathrm{Q}_{\mathrm{v}}=\mathrm{C}_{\mathrm{dv}} A_{\mathrm{v}} \sqrt{\frac{2}{\rho} P}
\end{aligned}
$$

$\mathrm{K}_{\mathrm{c}}$ and $\mathrm{C}_{\mathrm{dv}}$ are obtained experimentally by measuring the flow characteristics of the equation as applied to the cavity of volume $V_{1}$, yields: 


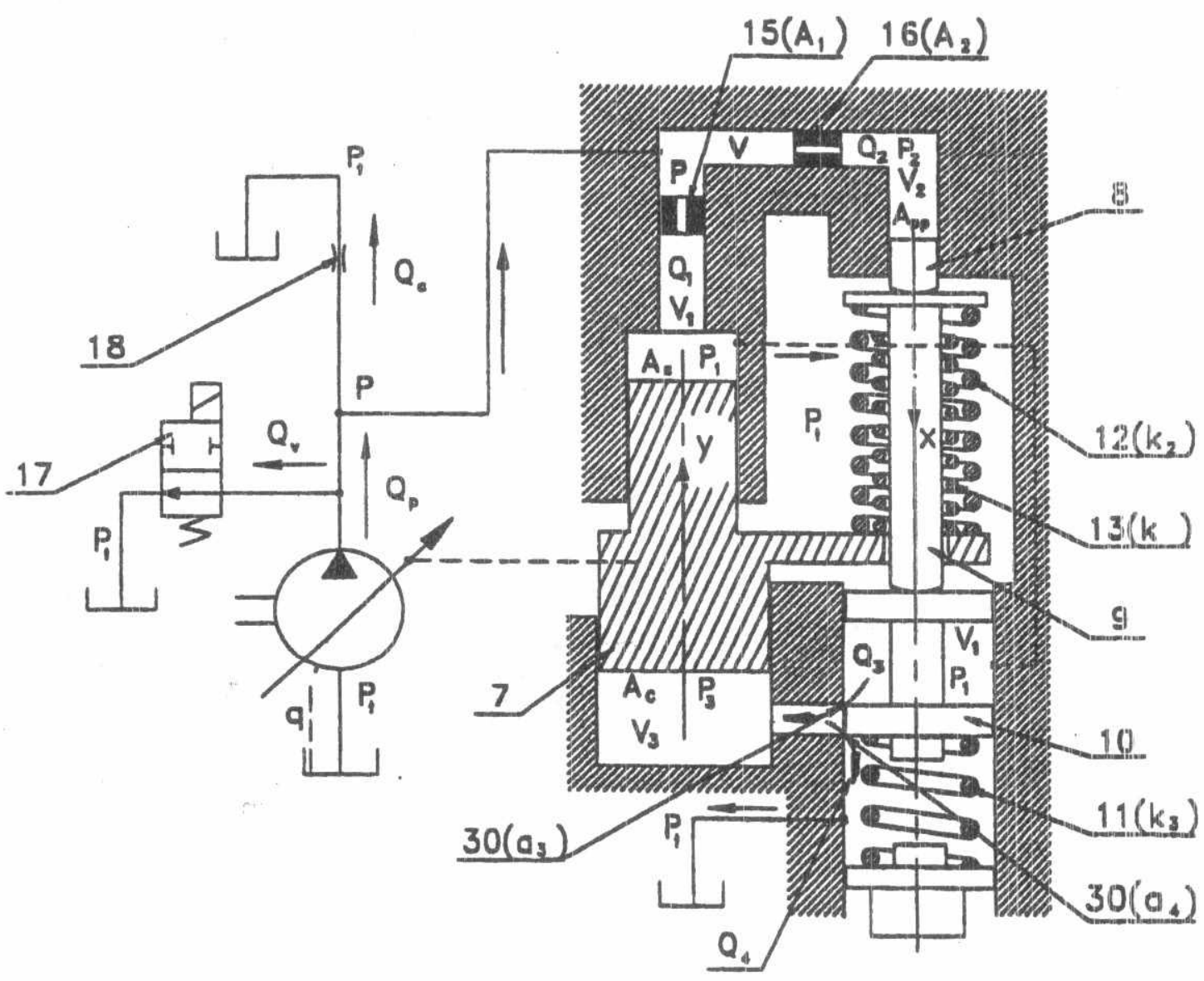

Fig.6. Scheme of the pump controller and loading elements.

$$
Q_{1}+A_{0} \frac{d y}{d t}=Q_{3}+\left(\frac{V_{1}-A_{8} y}{B}\right) \frac{d P_{1}}{d t}+q_{1}
$$

The flow rate $Q_{3}$ is given by:

$$
Q_{3}=C_{d 3} a_{3} \sqrt{\frac{2}{\rho}}\left(P_{1}-P_{3}\right) \mid \operatorname{sign}\left(P_{1}-P_{3}\right)
$$

The continuity equation as applied to the cavity of volume $V_{2}$, yields

$$
Q_{2}=A_{p p} \frac{d x}{d t}+\frac{\left(V_{2}+A_{p p} x\right)}{B} \frac{d P_{2}}{d t}+q_{2}
$$

The continuity equation as applied to the cavity of volume $V_{3}$, yields:

$$
Q_{3}=A_{c} \frac{d y}{d t}+\frac{\left(V_{3}+A_{0} y\right)}{B} \frac{d P_{3}}{d t}+Q_{4}+q_{3}
$$


The flow rate $Q_{4}$ is given by the following equation.

$$
Q_{4}=C_{d 4} a_{4} \sqrt{\frac{2}{\rho} P_{3}}
$$

The areas $a_{3}$ and $a_{4}$ change nonlinearly with the displacement $x$, as shown in Fig.5. The control piston, guide rod and the spool are subjected to pressure, spring, jet described by the following equations

$$
\begin{aligned}
& m_{x} \frac{d^{2} x}{d t^{2}}+f_{x} \frac{d x}{d t}+K_{3}\left(x+x_{0}\right)+K_{2}\left(x+y+y_{0}\right)+F_{p x}+F_{x}+F_{j x}=P_{2} A_{p p} \\
& F_{j x}=\frac{\rho Q_{3}^{2}}{C_{0} a_{3}} \cos \varphi \frac{\rho Q_{4}^{2}}{C_{0} a_{4}} \cos \varphi \\
& F_{r x}=\left\{\begin{array}{ll}
\left(K_{r} x+f_{r} \frac{d x}{d t}\right) \operatorname{sign}\left(x_{\max }-x\right) \text { if } x_{\text {max }} \leq x \leq 0.01 \mathrm{~mm} \\
0 & \text { if } x_{\text {max }}>x>0.01 \mathrm{~mm}
\end{array}\right\} \\
& F_{x}=\left\{\begin{array}{ll}
K(x+y-\delta) & \text { if }(x+y)>\delta \\
0 & \text { if }(x+y) \leq \delta
\end{array}\right\}
\end{aligned}
$$

The servo piston is subjected to pressure, spring, control and seat reaction forces and its motion could be described by the following equations

$$
\begin{aligned}
& m_{y} \frac{d^{2} y}{d t^{2}}+f_{y} \frac{d y}{d t}+K_{2}\left(x+y+y_{0}\right)+F_{r y}+F_{x}=P_{3} A_{c}-P_{1} A_{c} \\
& F_{r y}=\left\{\begin{array}{ll}
\left(K_{r} y+f_{r} \frac{d y}{d t}\right) \operatorname{sign}\left(y-1 * 10^{-5}\right) & \text { if } y_{\max } \leq y \leq 0.01 \mathrm{~mm} \\
0 & \text { if } y_{\max }>y>0.01 \mathrm{~mm}
\end{array}\right\}
\end{aligned}
$$

The reactions forces $F_{x x}$ and $F_{y y}$ of the seats are introduced in the model by considering an equivalent stiffness of the seat material $K_{r}$ and damping coefficient $f_{r}$ when the moving element comes in of the seat material. These forces appear only

Equations (1) to (30) are the geverning equations describing the dynamic behavior 


\section{COMPUTER SIMULATION}

The pump simulation is carried out by the exploitation of equations (1) to (30) using the TUTSIM simulation program, version 7, [6]. This program enable to simulate the dynamic systems described by highly nonlinear mathematical model including algebraic and differential equations. The simulation by this program is based on the functional representation of the mathematical model in terms of the available TUTSIM function tools. The TUTSIM functions enable to take into consideration, practically, all of the pump nonlinearities as well as the generation of the recommended inputs. The numerical values of the pump constructional and operational parameters were obtained from the data sheets delivered by the producer [7], and by direct measurements carried out on the pump elements. The static characteristics of the studied pump can be evaluated by solving the pump governing equations numerically in the steady state.

\section{EXPERIMENTAL WORK}

The experimental work aims at validating the simulation program in the different static and dynamic operating conditions. The hydraulic circuit of the used test rig is shown in Fig.7. The suction and discharge lines of the test pump are connected directly to the suction line port and the flow meter port, respectively. The tested pump (16) is driven by means of a hydraulic motor (13). The pump speed is measured by means of a tachometer (15), and controlled by changing the speed of the driving motor (5). The test pump delivery line is equipped with a pilot operated relief valve (28). The pump exit fluid flow through the opened DCV (17) and orifice (18) to the tank, through the flow meter (20). The DCV acts as a by-pass line in this case. By communicating the electric power to the solenoid of DCV, the valve closes and the exit pump flow is forced through the loading orifice. The used DCV is equipped with a powerful AC solenoid. During the steady state measuremenis shutoff valve (30) is closed and the pressure $P$ is controlled by throttle valve (29). During the transient mode of operation, the shut-off valve is widely opened and the throttle valve is completely closed.

\section{Measurement of the Pump Static Characteristics}

The experimental determination of the static characteristics of the studied pump is carried out by measuring the pump discharge flow $Q_{p}$ at different values of the supply pressure $P$. The supply pressure $P$ is controlled by the throttle valve and is indicated by the pressure gauge $(21)$. The corresponding pump discharge $Q_{p}$ is measured by the flow meter (20). Measurements were carried out for different pump speeds, 550, 800, and $1000 \mathrm{rpm}$ at the same presetting pressure. The flow rate $\mathrm{Q}_{\mathrm{p}}$ is also measured at different values of the presetting pressure. The Experimental and theoretical results are plotted in Figs 9 and 10. 
1. Tonk.

2. Auxlliary pump.

3. Nain pump.

5. Varloble speed mator.

6. Non Return volve.

7,8 Rellef valves

Q,10 Dirtetional entrol valves.

11. Cherge pressure elroult.

12. Hotn power elreult.

13. Hrdroulle mator.

i4. Mator drive shate.

15. Techemeter.

16. Tested pump.

17. Dirutional contrel valve (OCV).

18. Fised lasding orffios.

19. Frasure gouge

20. Digitel flow meter.

21. Digitel presesurs fndicoter.

22. Rellof vahess.

23. Pump suetlen pressure geugs.

24 Pump auetion port.

25. Flaw maier port.

26. Remort control.

27. Cooler.

28 Retlet vahys.

29. Throtils valve.

30. Shut-otf value.

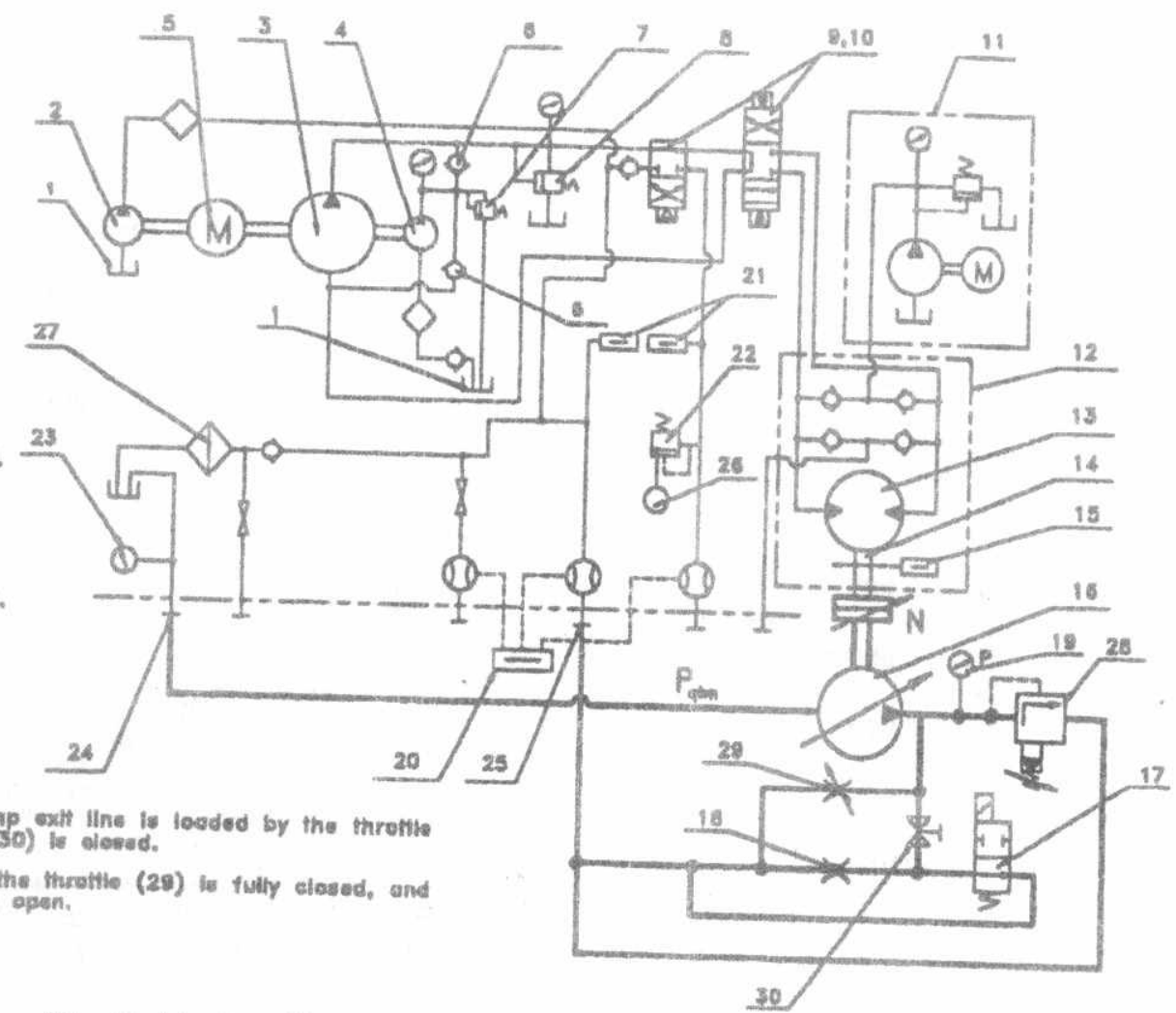

Fig.7. Hydraulic circuit of the test rig

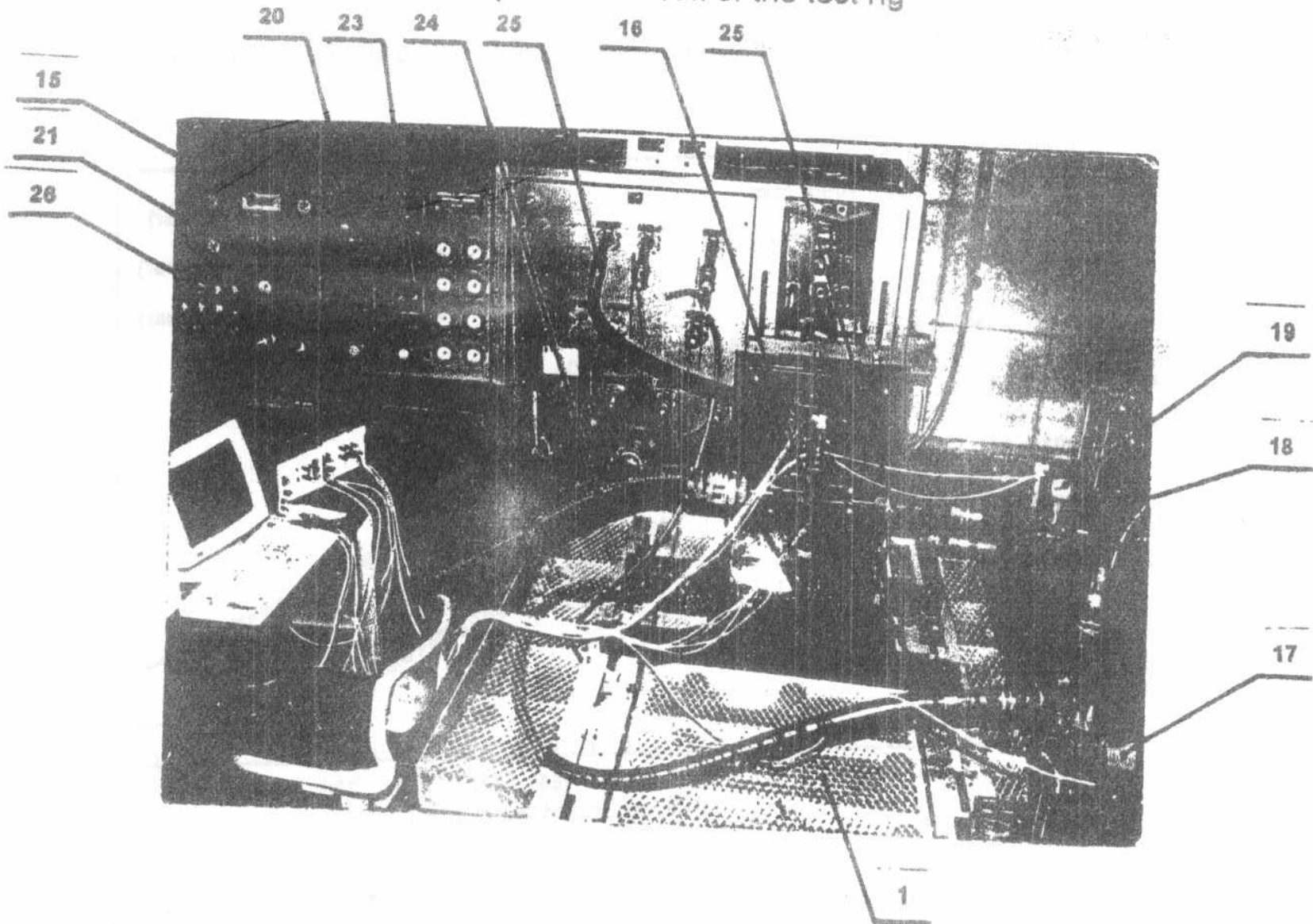

Fig.8. Photo of the experimental set-up 


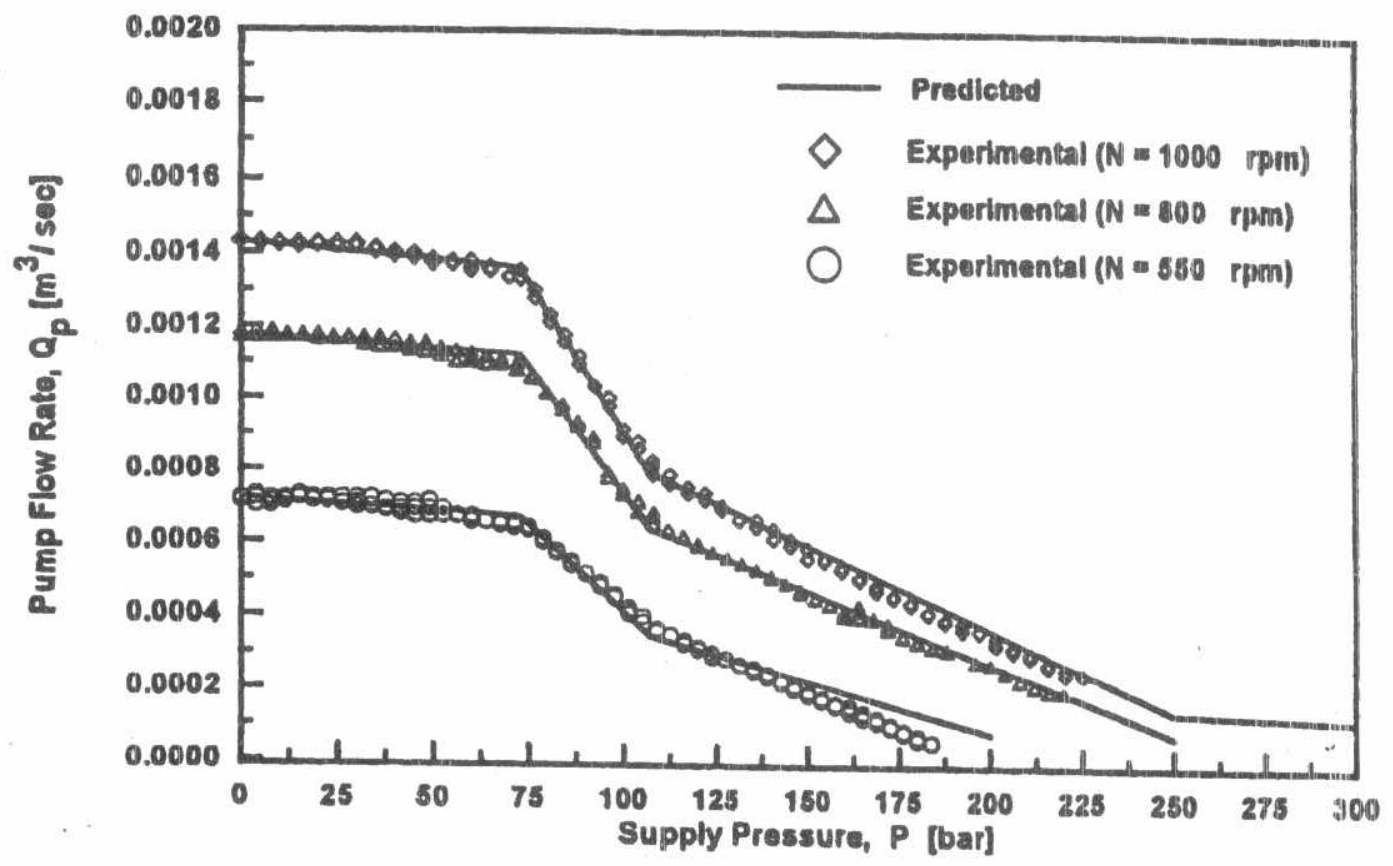

Fig.9. Steady state flow pressure characteristics, for different pump speeds.

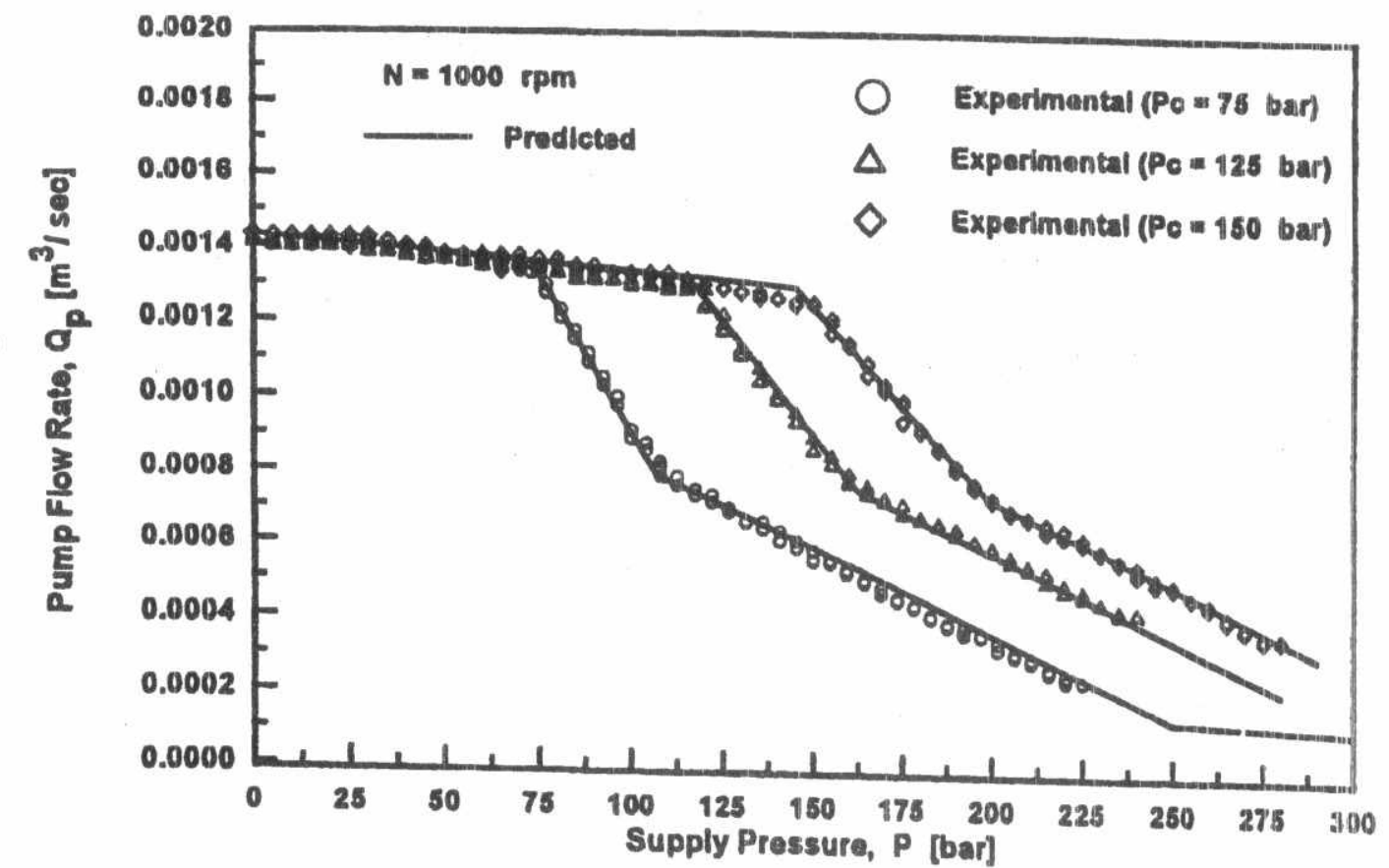

Fig.10. Steady state flow pressure characteristics for different presetting of the adjusting spring and constant pump speed 


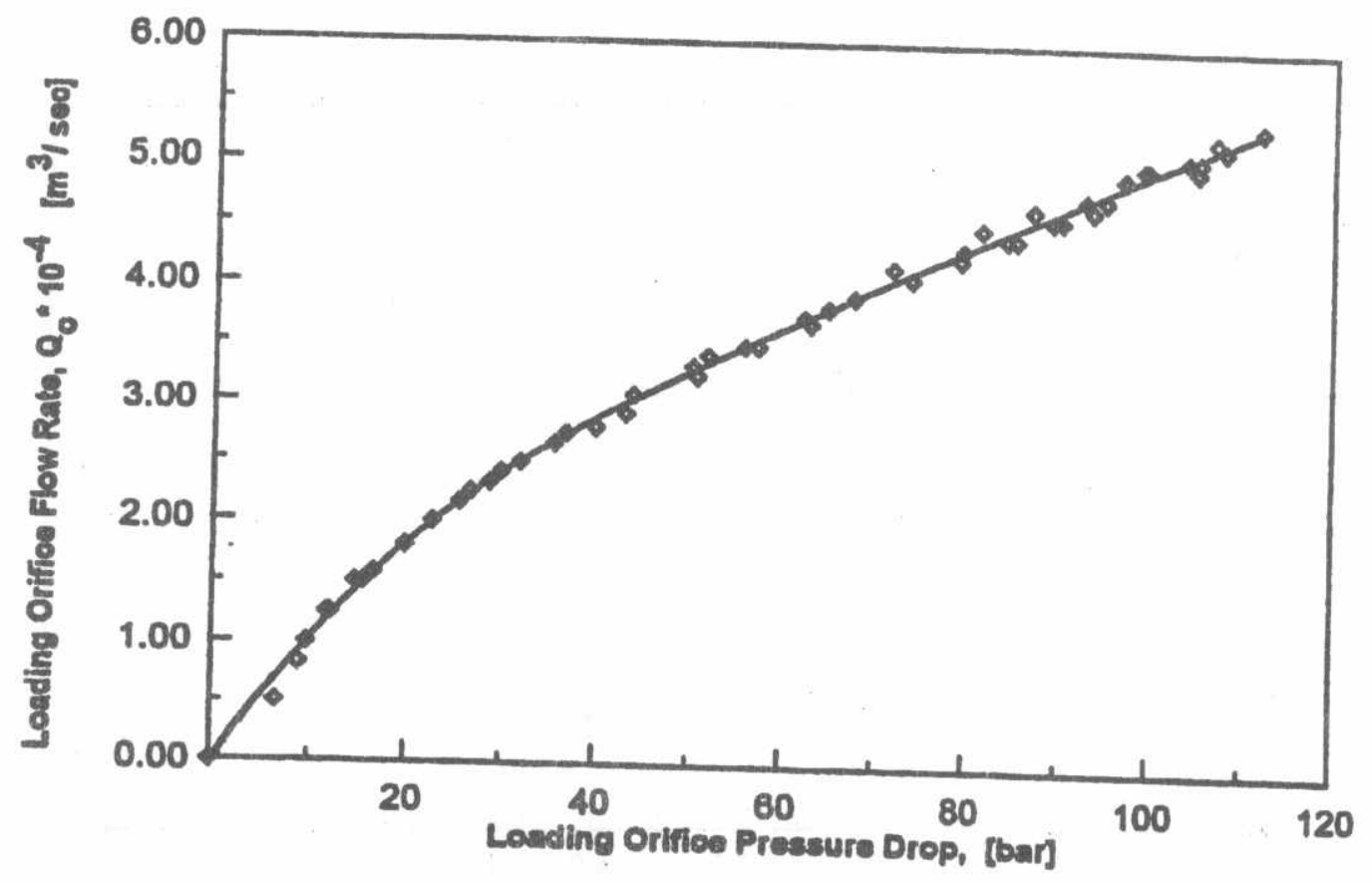

Fig.11. Flow pressure characteristics of the loading orifice.

\section{Pump Loading}

The resistance of the pump circuit, the variation of loads and the flow demands are represented in this work by a sharp edged loading orifice (dianteter $=2.5 \mathrm{~mm}$ ) fitted at the pump exit line, Fig.7. This orifice and DCV are used to introduce sudden change in the pump exit pressure. When the DCV is switched on the discharge of pump passes to the tank via the DCV widely opened restriction area. When the valve is switched off, its restriction closes and the discharge flow passes to thank via the loading orifice. A representative model of the loading orifice and the DCV are deduced on the basis of experimental measurements and used for the theoretical

\section{Fixed area loading orifice}

The characteristics of the loading orifice are evaluated out by measuring the pressure difference $\left(P-P_{t}\right)$ and the corresponding flow rate $Q_{c}$. A least square curve fitting is carried out to the measured values and the results are plotted in Fig.11. The

$$
Q_{c}=1.65 * 10^{-7} \sqrt{\left(P-P_{t}\right)}
$$




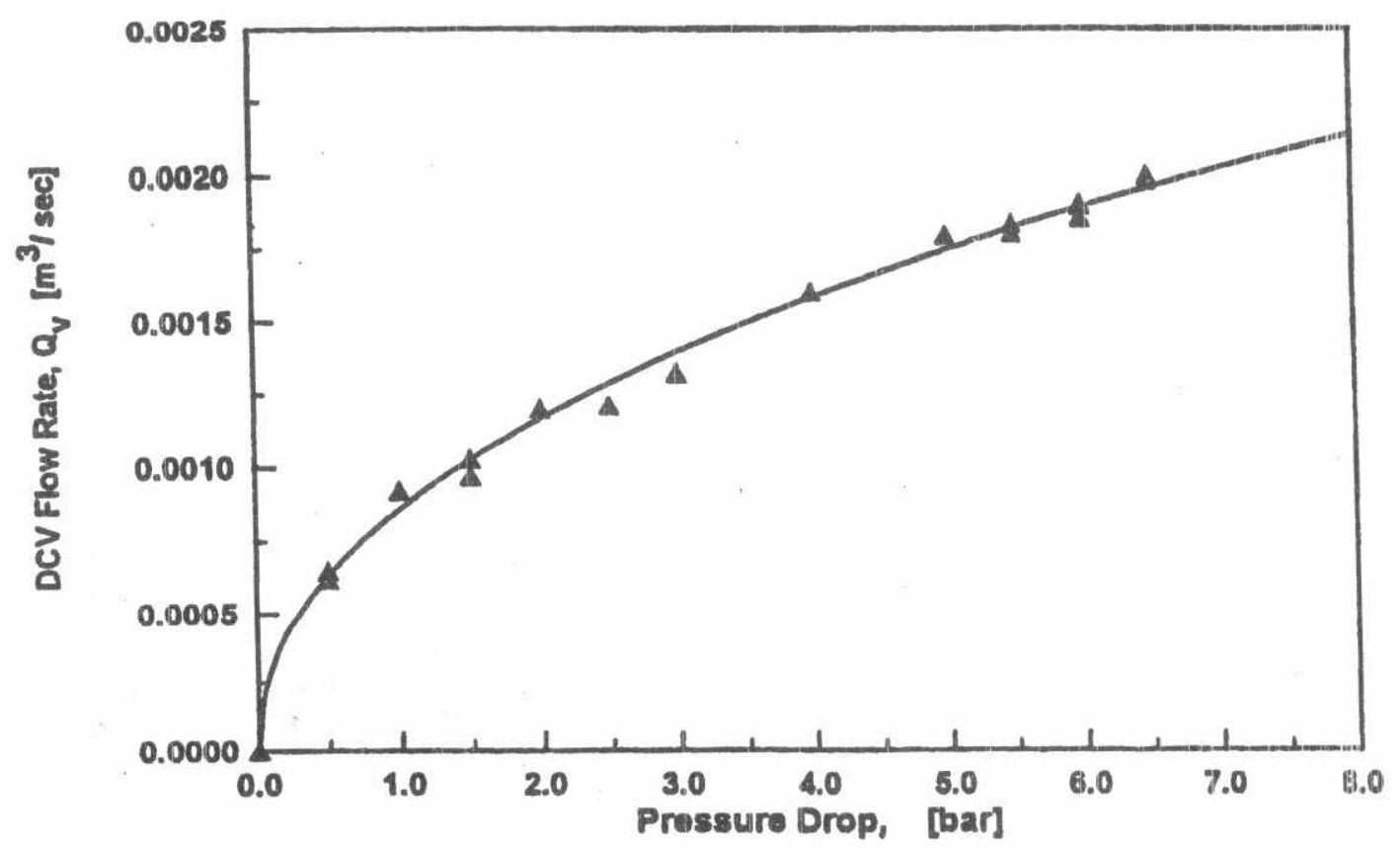

Fig.12. Steady state flow characteristics of the DCV.

\section{Directional control valve (DCV)}

For precise modeling of the pump loading, the static and dynamic characteristics of the DCV were measured. The measured steady state $P-Q$ relation of the DCV, when fully opened is shown in Fig.12. The same figure carries a least square fitted curve, whose equation is found to be:

$$
Q_{v}=K_{v} \sqrt{\Delta P}=2.42 * 10^{-6} \sqrt{\Delta P}
$$

The measured values are used to find the discharge coefficient of the DCV restriction, $\mathrm{C}_{\mathrm{dv}}$, as follows;

$$
C_{c v}=K_{v} / A_{v m} \sqrt{2 / \rho}
$$

The area $A_{v}$ is given by the following expression;

$$
A_{v}=\pi D_{s} x^{\prime}
$$

The values of $x^{\prime}$ and $D_{s}$ are obtained from a direct measurement of the DCV parameters, then the value of $C_{d v}$ is found to $b e, C_{d v}=0.59$. 


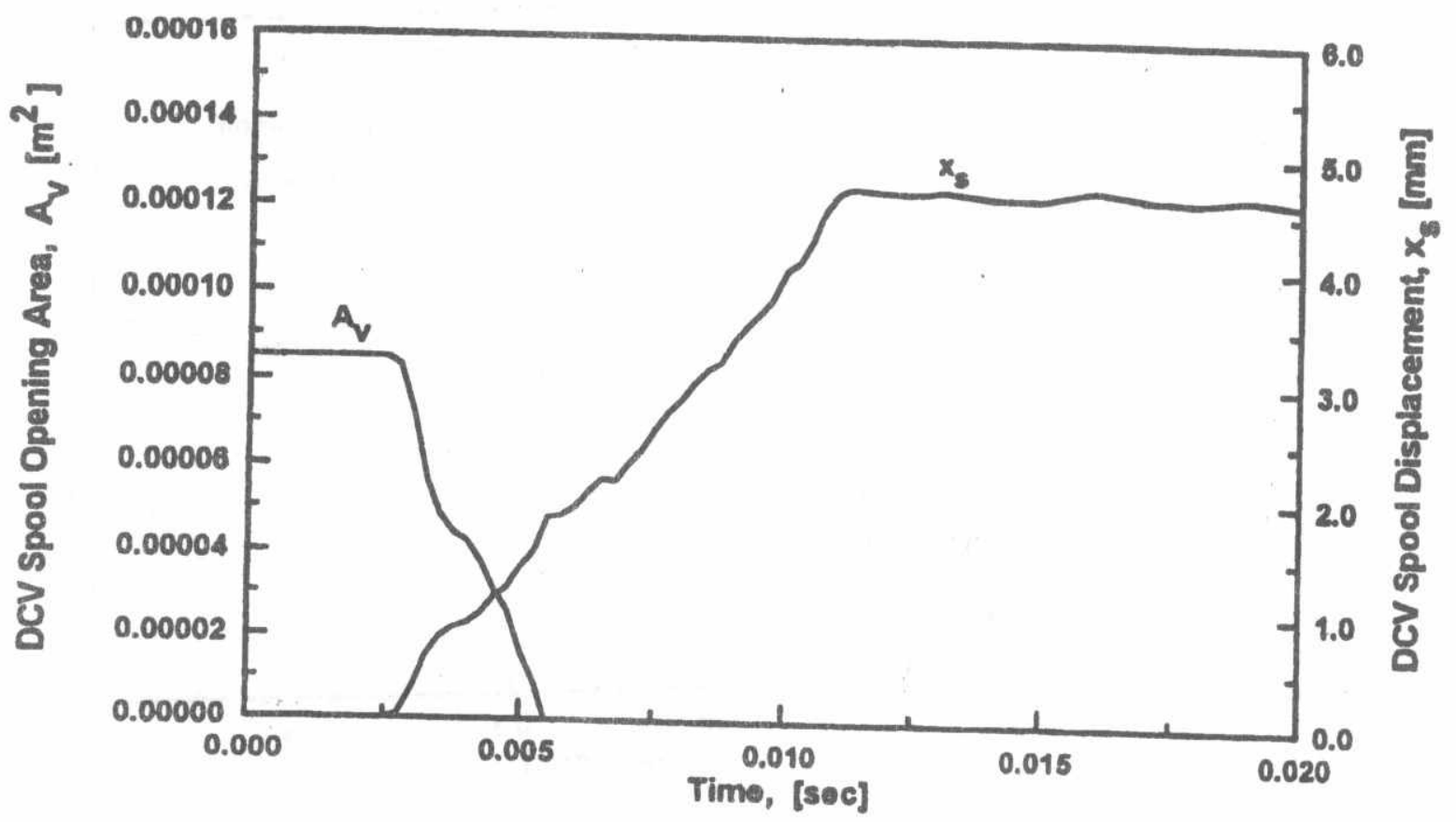

Fig.13. Transient variation of DCV spool displacement and throttlind area.

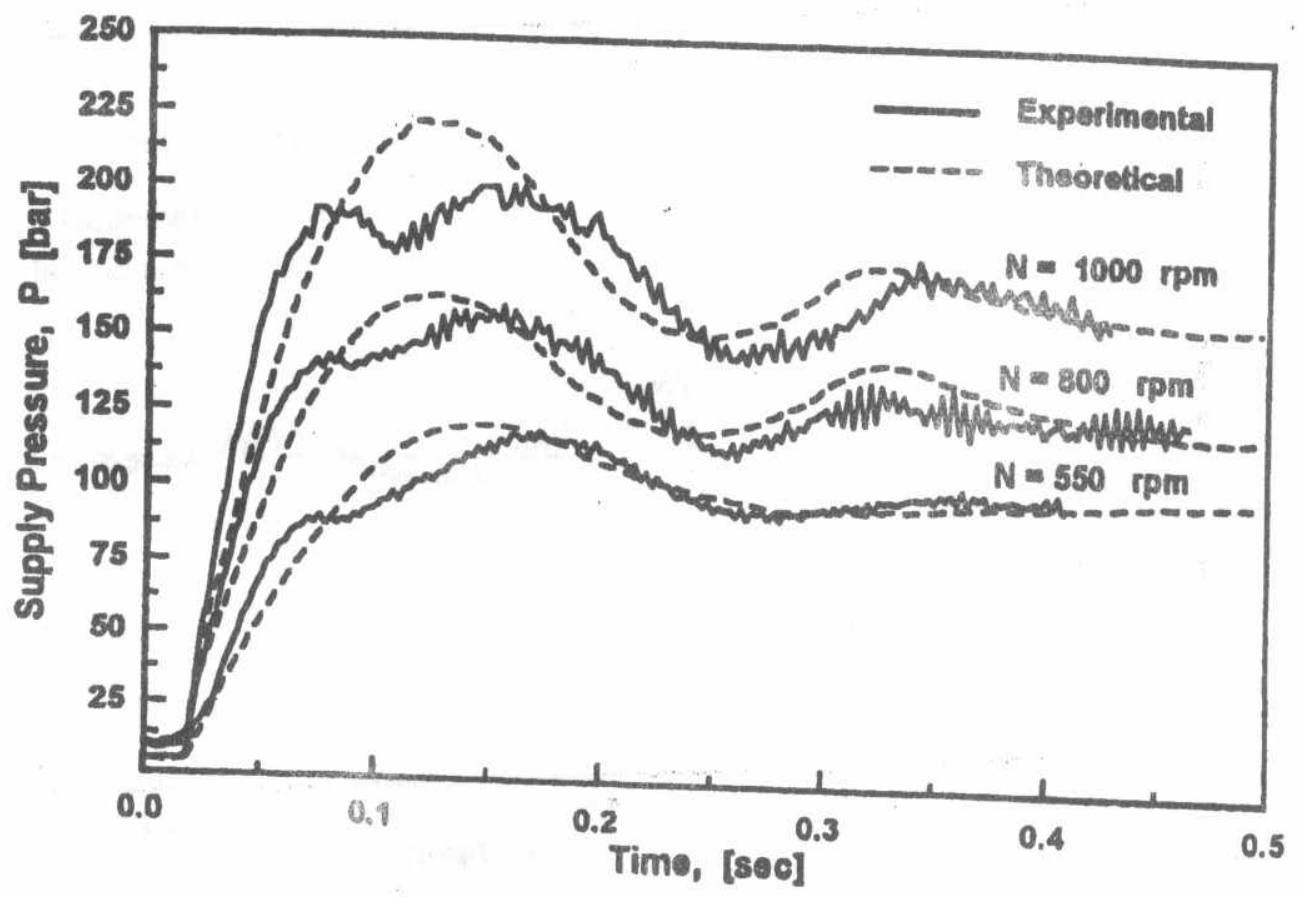

Fig. 14. Transient response of pump exit pressure to rapid closure of its exit line for different pump speeds. 


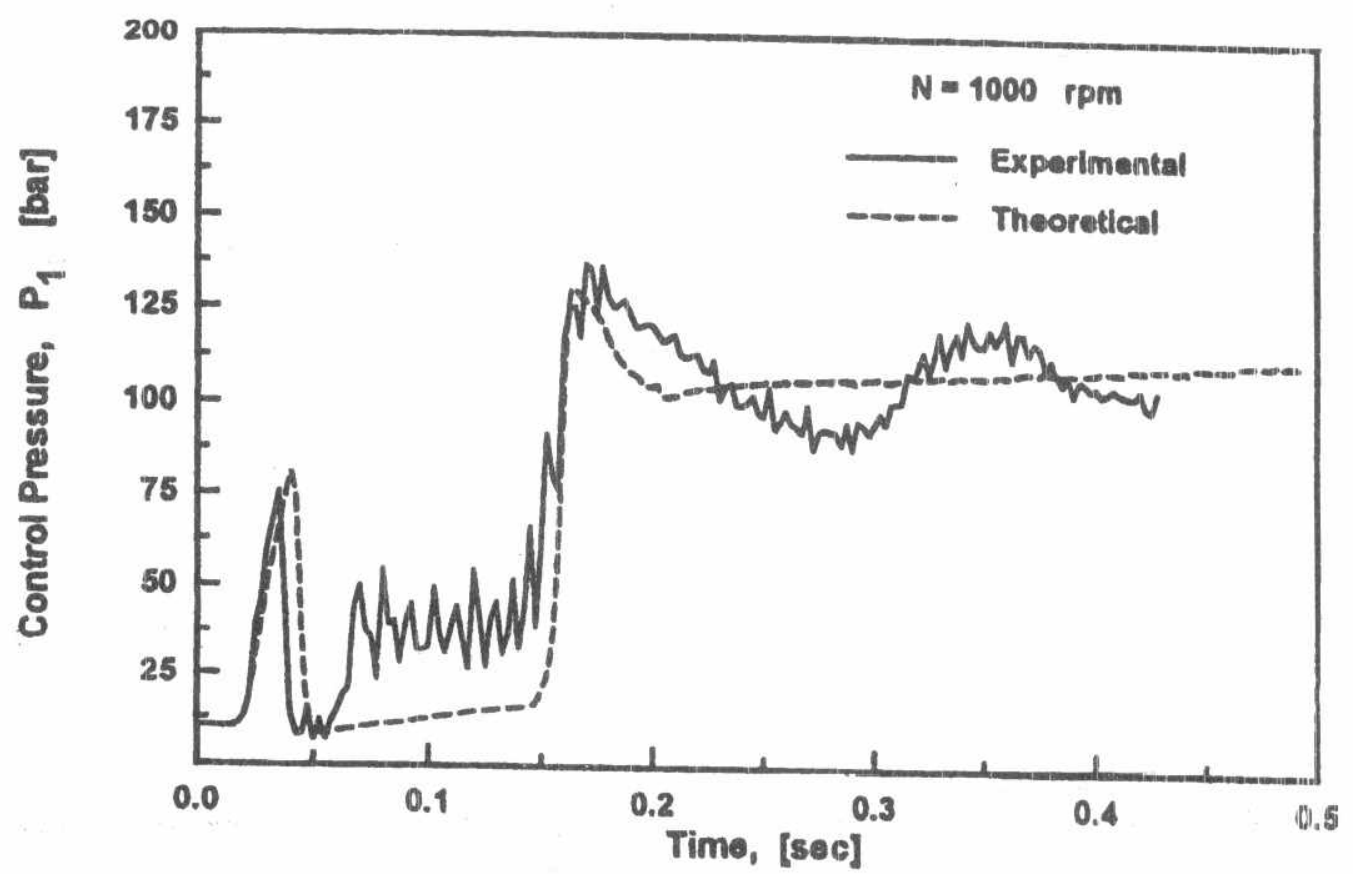

Fig.15.a. Transient response of control pressure $P_{1}$ to rapid closure of exit line, at $n=1000 \mathrm{rpm}$

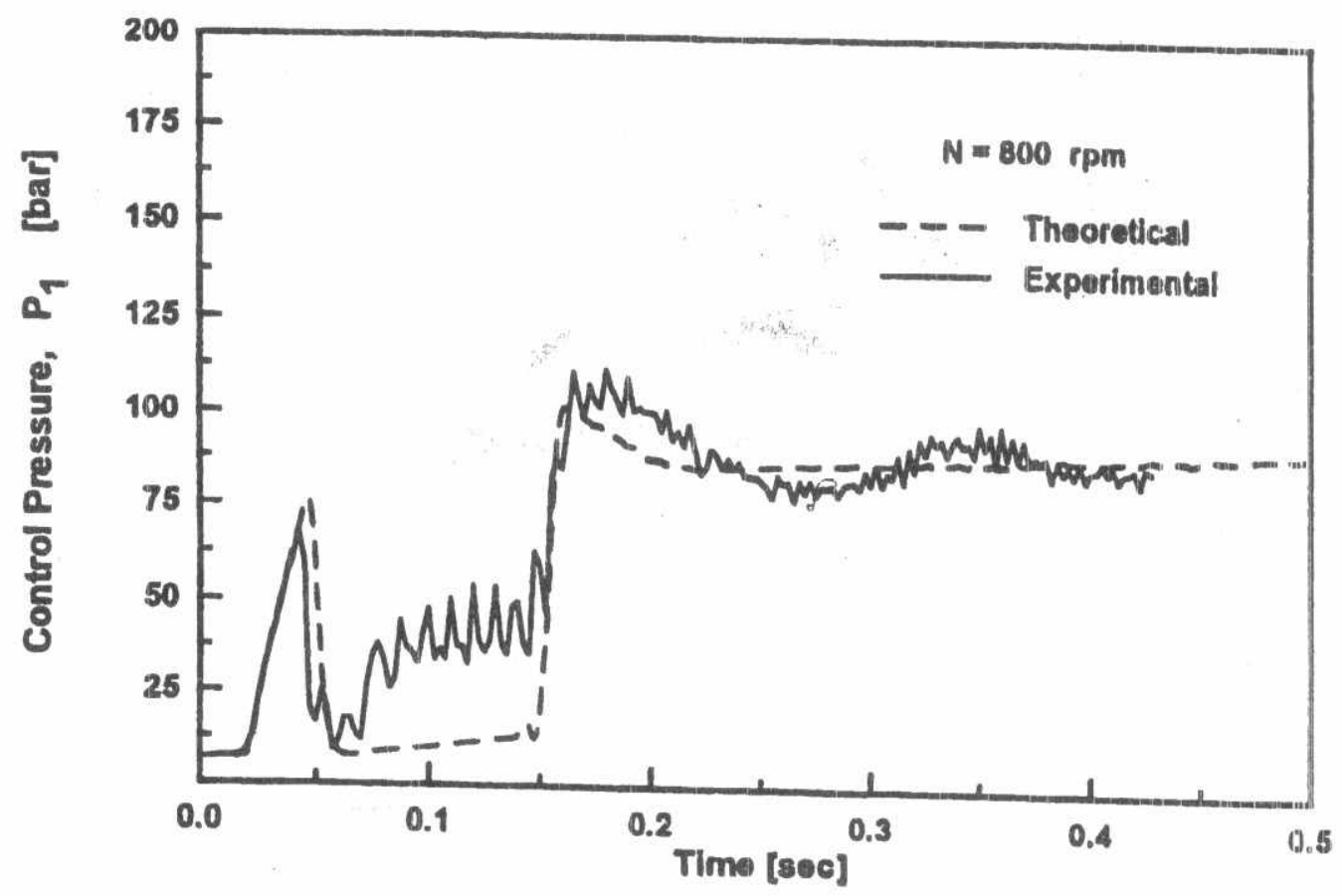

Fig.15.b. Transient response of control pressure $P_{1}$ to rapid closure of exit line, at $n=800 \mathrm{rpm}$ 


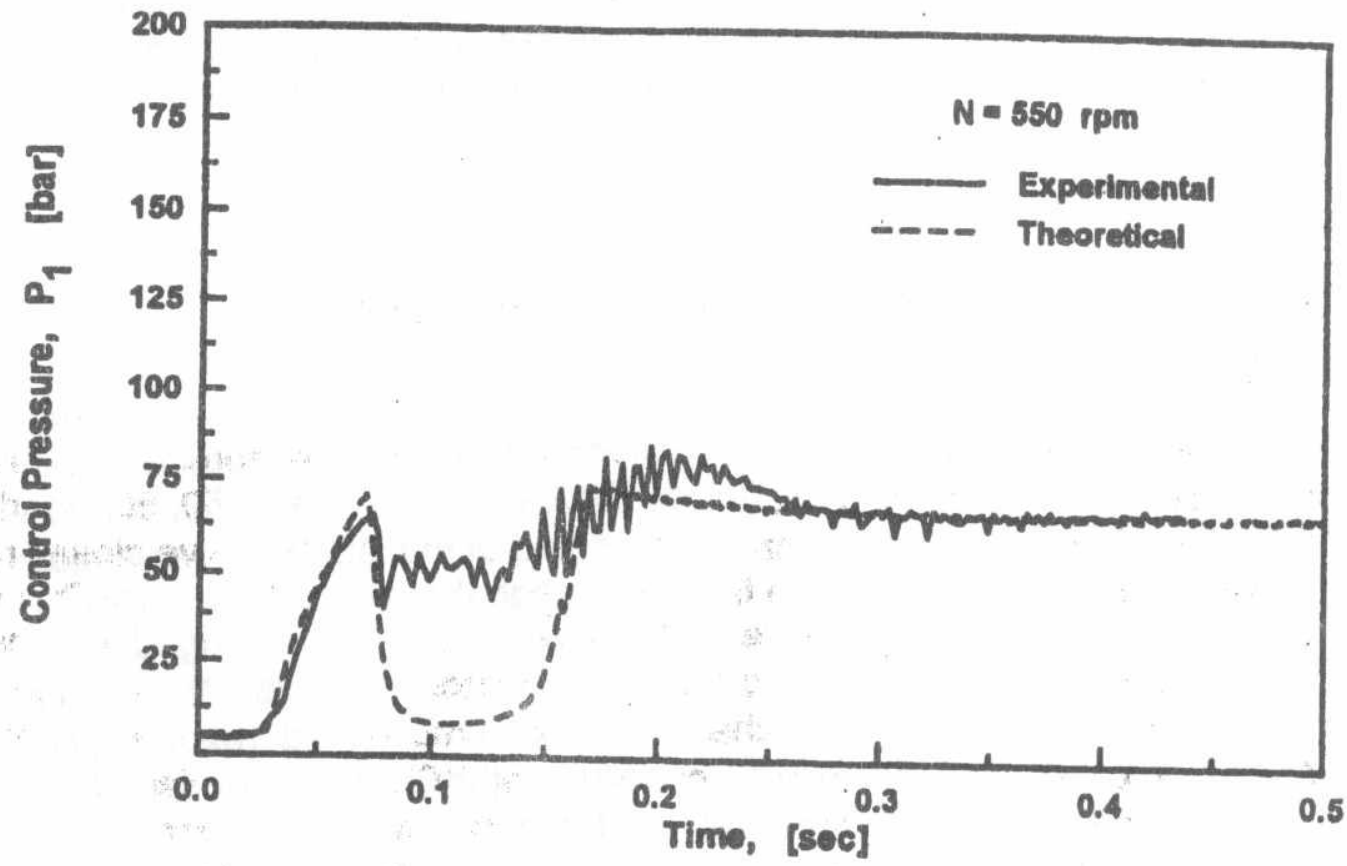

Fig.15.c. Transient response of control pressure $P_{1}$ to rapid closure of exit line, at $n=550 \mathrm{rpm}$

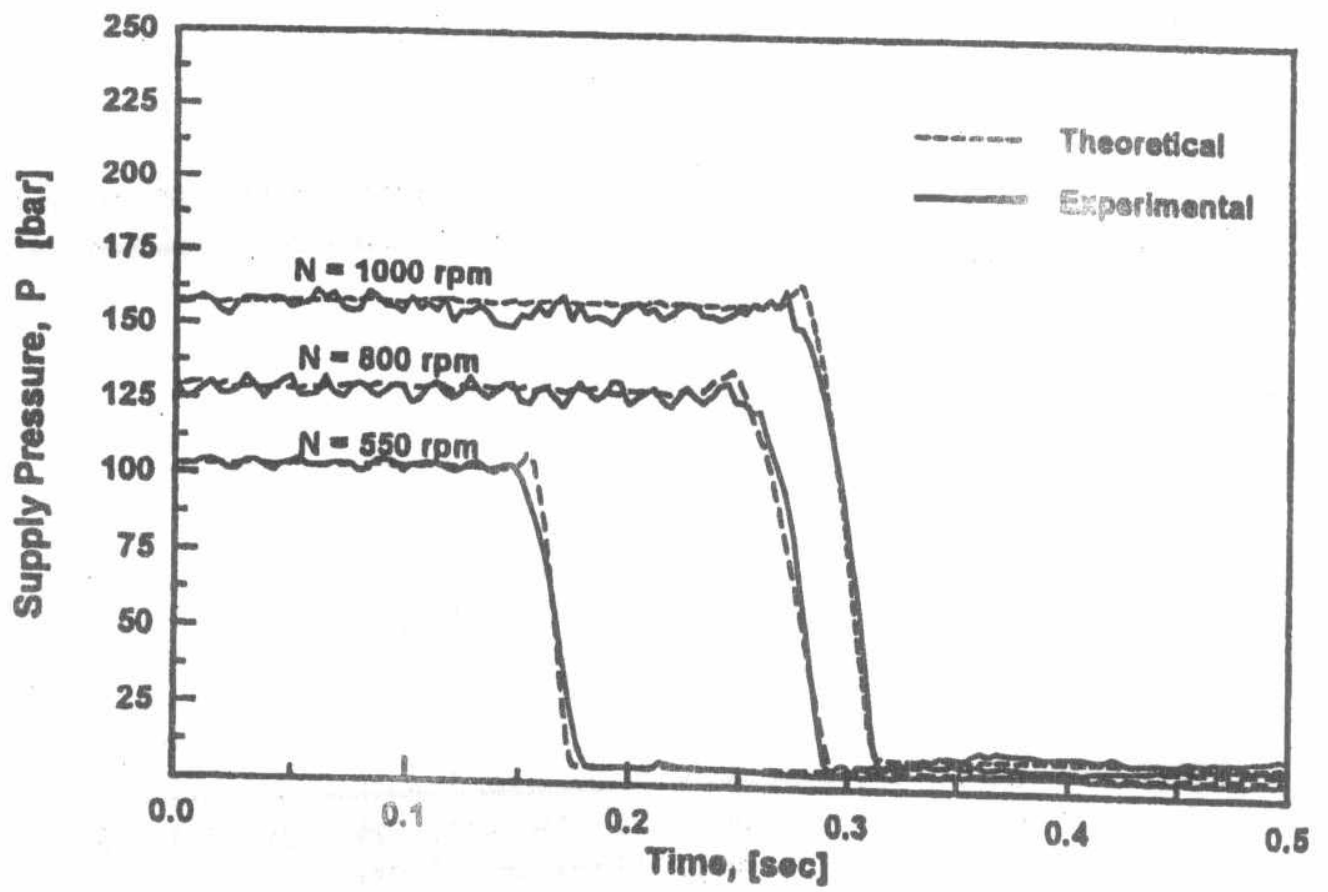

Fig. 16. Transient response of exit pressure $P$ to rapid opening of the DCV for different pump speeds. 
The measured transient response of the DCV displacement $x_{0}(t)$ is given in Fig. 13 . The record of displacement time relation starts by a triggering signal, which communicate the electric power to the electric solenoid. The experimental results of DCV transient response are used to calculate the transient variation of its throttling area. The calculation results are also plotted in Fig.13, and introduced in this computer simulation program of the pump by the following relation.

$$
Q_{v}=C_{a v} A_{v} \sqrt{2\left(P-P_{t}\right) / \rho}
$$

\section{Measurement of the Pump Pressure Transient Variation}

The pump exit pressure $P$ and control pressure $P 1$ are measured by using Two pressure transducers. The transient response of the pump pressures due to suclden increase of it's load, is carried out for different pump speeds, 550, 800, and 1000 $\mathrm{rpm}$. When energizing the electronic solenoid of the DCV, the valve closes rapidly and the pump delivery is forced to flow through the exit-loading orifice. This orifice increases the pump exit pressure. The test rig is arranged such that the communication of electric current to the DCV solenoid triggers the date acquisition system. The obtained results together with the simulated results are polotted in Figs.14\&15. By opening the electric circuit of the DCV electric solenoid, the valve opens a low resistance by-pass line and the total exit line resistance clecreases which decreases the pump exit pressure. The transient response of the pump pressure $P_{1}$ due to sudden decrease of the pump load is also evaluatec experimentally at different speeds. The obtained results are plotted in Fig. 16.

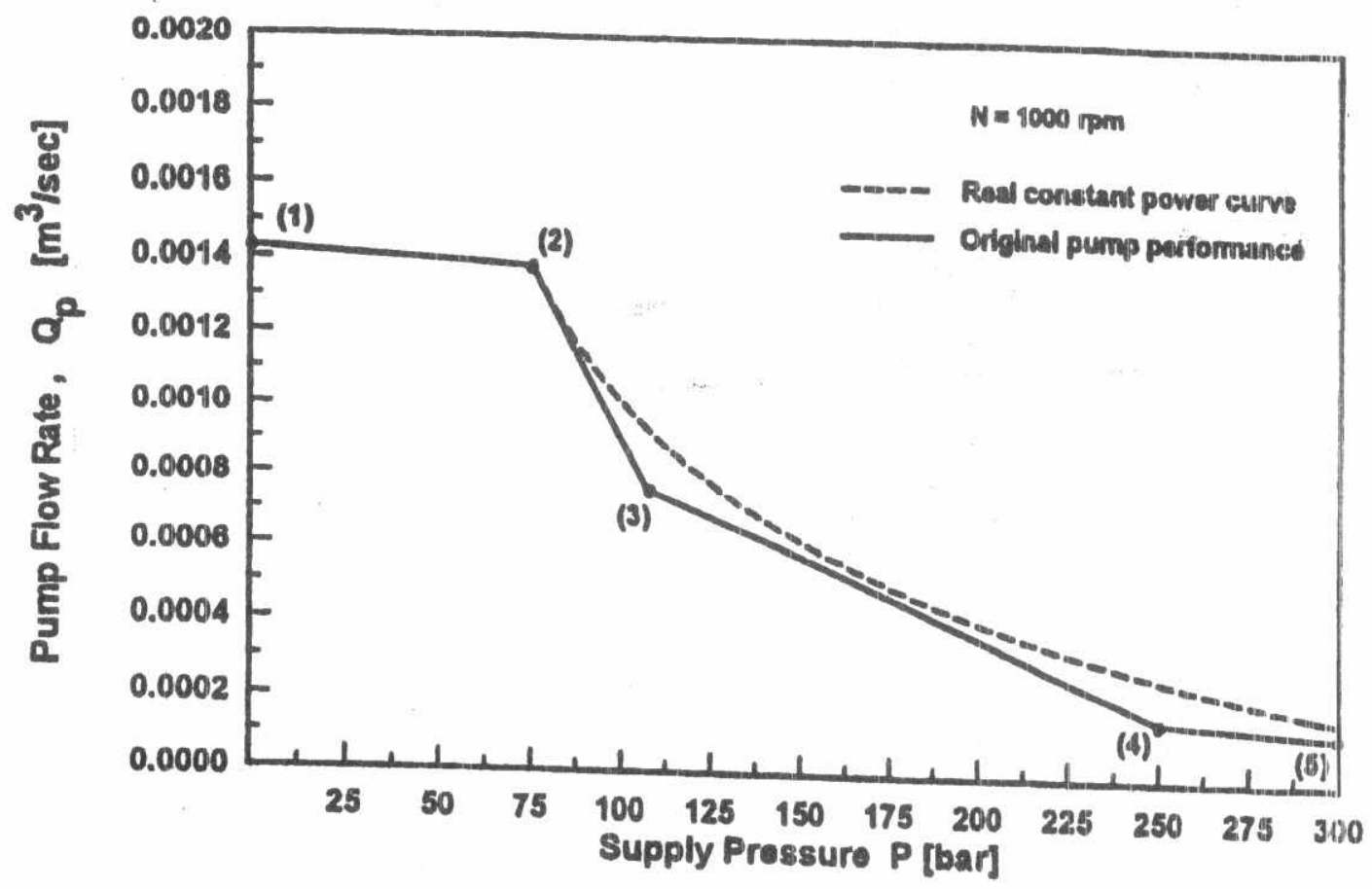

Fig.17. Actual and required steady state $Q(P)$ relation. 


\section{ANALYSIS OF RESULTS}

\section{Steady-State Mode of Operation}

The steady state relation between the pump flow rate and its exit pressure is predicted theoretically and experimentally and plotted in Figs 9\&10. These figures show that, the used controller produces a two straight-line steady state relationship. It does not produce the required hyperbolic $Q(P)$ relation expressing the required constant power, Fig.17. The actual output power is less than the maximum available power, which is the main disadvantage of this controller design. But the simplicity of controller design and its high reliability make it more popular. The examination of Figs.9\&10 shows that, the theoretical and experimental results are in good agreement during the whole operating pressure range, which insures the validity of the developed model in the steady-state mode of operation.

\section{Transient Mode of Operation}

The transient response of the pump delivery pressure $P$ and control pressure $P_{1}$ to sudden throttling of its exit lines, for several values of pump speed $N$, is predicted theoretically and experimentally. The results are plotted in Figs. 14\&15. The same figures carry the experimental results. The study of Fig.14 shows the following:

- The pump response presents a settling time within $0.4 \mathrm{sec}$. This settling time is relatively long, due to the small stiffness of springs $K_{1}$ and $K_{2}$, and the relatively large inertia of moving parts $m_{x}$ and $m_{y}$.

- A maximum overshoot of about $30 \%$.

- The experimental results show remarkable transient and steady state pressure pulsation. This pulsation doesn't appear clearly in the theoretical results, which could be attributed to

1. Neglecting the effect of exit short line.

2. Considering the exit line volume constant, while it changes due to the reciprocating motion of pistons and engagement and disengagement of
different piston chambers.

3. Neglecting the effect of pressure forces acting on the control plate and consequently on the servo piston. Apart from the previously discussed pressure pulsation, the theoretical and
experimental results are in good agreement.

Figure 15 shows the transient response of pressure $P_{1}$. The increase of pump exit pressure $P$ increases the pressure $P_{1}$. Referring to Fig.6, When the pressure $P_{2}$ reaches the value needed to overcome the spring forces, the control piston, guide rod, and spool displace and the two sides of the servo piston are communicated together through the opening area. This leads to rapid decompression of oil in the cavity of volume $V_{1}$ and then the pressure $P_{1}$ decreases and $P_{3}$ increases. But, due 
to the continuos supply of oil from the pump exit line through the first damping orifice, the pressure $P_{1}$ rapidly increases to reach its steady state value. These stages of transient variation are clearly indicated in Fig.15. The theoretical and experimental results of transient variation of pressure $P_{1}$ aro in a good agreement from point of view of the general shape of response. But, the experimental results present considerable pressure pulsation and transient oscillations compared with the theoretical results. The difference between the theoretical and experimential results could be attributed to the previously mentioned reasons in addition to the following;

- The discharge coefficients of orifices $A_{1}$ and $A_{2}$ are assumed constant.

- The pressure variations are very sensitive to the flow rates due to great Bulk's modules of oil. Therefore, considerable difference could appear between the experimental and theoretical results due to the assumption of constant discharge coefficient.

Considering these factors, the obtained theoretical results could be accepted and good agreement with experimental results could be concluded.

\section{CONCLUSION}

The static and dynamic behavior of a variable displacement bent axis axial piston pump with power controller is investigated theoretically and experimentally. A mathematical model is deduced to predict the performance of the studied pump and its hydraulic servo controller. The developed model, which takes into consideration the basic pump and controller nonlinearities is used to develop a computer simulation program for the pump. The steady state flow-pressure characteristics and pump transient response are predicted theoretically by using the simulation program.

The pump static and dynamic characteristics are also evaluated experimentally. The experimental work aimed at validating the pump mathematical model and the simulation program. The study showed good agreement between theoretical and experimental results in the steady state and transient modes of operation. The study provides good foundation for future work aiming at improving the pump performance by finding out optimum constructional parameters.

\section{REFERENCES}

1 Manring, N.D. "The Torque on the Input Shaft of an Axial-Piston Swash-Plate Type Hydrostatic Pump" Journal of Dynamic system, Measurement, and control March 1998, Vol. 120, pp 57-62.

2 El-Sayed O.G., "An Investigation into the static and Dynamic Performance of a Class of Variable Displacement Axial Piston Pump with Power Controller", Ph.D. Thesis, Faculty of Engineering, Zagazig Univ., Egypt, 1997.

3 Manring, N.D and Johnson, R.E. "Modeling and Designing a Variable-Displacernent Open-Loop Pump" Journal of Dynamic system, Measurement, and control, June 1996, vol. 118, pp 267-271. 
4 Kaliafetis, P., Costopoulos, T.H., "Modelling And Simulation of An Axial Piston Variable Displacement Pump With Pressure Control" Mechanism and Machine Theory, Vol. 30, No. 4, pp. 598-612, 1995.

5 Kiyoshi, I. and Masakasu, N. "Study of The Operating Moment of A Swash Plate Type Axial Piston Pump: First Report" J. of Fluid Control, vol. 22, Issue 1, pp. 7-29,

6 Meerman, "TUTSIM Ver. 7 Users Manual, Meerman Automation, The Netherlands

7 Mannesmann Rexroth, "Variable Displacement Pump A7VO," Data sheet No. RE 92203/03.92, Mannesmann Rexroth Gmbh, Germany, 1992, pp 1-20.

8 Edge, K. and Darling, J." Cylinder Pressure Transient In Oil Hydraulic Pumps With Sliding Plate Valves" Proceedings, $2^{\text {sd }}$ Int. Conference on Fluid Power Transmission And Control, Hangzhou, China, pp.250-256,1989.

9 Edge, K.A., and Darling, J., "The Pumping Dynamics of Swash Plate Piston Pumps" Journal of Dynamic Systems, Measurement, and Control, Vol. 111, pp. 307-312, June 1989.

10 Zhang, L.Y. and Zhao, C.N. "Measurement And Simulation Model Study of Cylinder Pressure Transient In An Axial Piston Pump" Proceeding of the $2^{\text {sd }}$ national conference on Fluid Power Transmission And Control, Hangzhou, China, pp.471476, 1989.

$11 \mathrm{Kim}$, S. D., Cho, H. S., and Lee, C.O, "A Parameter Sensitivity Analysis For The Dynamic Model of A Variable Displacement Axial piston Pump" IMechE, Proc. Inst. Mech. Engrs, Vol. 201, No. C4, 1987.

12 Mannesmann Rexroth," Variable Displacement Pump A8VO," Data sheet No. RE 3010103.87, Mannesmann Rexroth Gmbh, Germany, 1987, pp 1-16.

13 Zeiger, G. and Akers, A." Dynamic Analysis of An Axial Piston Pump Swash plate Control" Proc. Inst. Mech. Engrs., vol. 200, no. C1, pp.49- 58,1986.

14 Lin, S.J, Akers, A., Zeiger, G., 1985, "The Effect of Oil Entrapment in an Axial Piston Pump" J. of Dynamic Systems, Measurement, and Control, vol. 107, Dec. 1985, ASME, Vol. 107, pp. 246-253.

15 Yamaguchi, A. and Takabe, T. "Cavitation In An Axial Piston Pump" Bulletin of the JSME, vol. 26,no. 211, January 1983, pp. 72-78.

16 Yamaguchi, A. and Ishikawa, T. "Characteristics of Displacement Control Mechanisms In Axial Piston Pumps" Bulletin of the JSME, vol. 22, no. 165, Pp.
356-361, 1979.

17 Zaki, H. and Baz, A., "On the Dynamics of Axial Piston Pumps" J. of Fluidic Quarterly, Vol. 11, Issue 1, March 1979, pp. 73-87. 